\title{
Crescimento econômico com restrição externa: uma análise da Lei de Thirlwall para os períodos FHC e Lula*
}

\author{
Economic growth with external restraint: \\ an analysis of the Thirlwall Law for the FHC and Lula periods \\ Érica Mendonça Marques ${ }^{\dagger}$ \\ Rodrigo Vilela Rodrigues ${ }^{\ddagger}$
}

\begin{abstract}
Resumo
Este artigo buscou avaliar os períodos dos governos FHC e Lula, bem como o período completo de 1995 a 2010, com objetivo de investigar em que medida o Brasil teve seu potencial de crescimento econômico limitado por restrições no balanço de pagamentos e quais diferenças observáveis entre os períodos. Para a análise empírica, adotou-se o procedimento econométrico de cointegração, empregado para estimativas de elasticidades-preço e renda da demanda por importação dos períodos, tendo como resultado um relaxamento na restrição externa no período Lula comparativamente ao governo FHC. Os resultados indicam que embora as restrições externas tenham reduzido durante o governo Lula em relação ao governo FHC, há evidências de que continuaram desempenhando papel relevante sobre a taxa de crescimento de longo prazo do Brasil.
\end{abstract}

Palavras-chave: Crescimento econômico; Lei de Thirlwall; restrição no balanço de pagamentos.

\begin{abstract}
This article sought to evaluate the periods of the FHC and Lula governments, as well as the entire period from 1995 to 2010, in order to investigate to what extent Brazil had its potential of economic growth limited by balance of payments constraints and observable differences between periods. For the empirical analysis, we adopted the econometric cointegration procedure, used to estimate the price and income elasticities of the import demand of the periods, resulting in a relaxation in the external constraint in the Lula period, compared to the FHC government. The results indicate that although external constraints decreased during the Lula administration compared to the FHC government, there is evidence that they continued to play a relevant role in Brazil's long-term growth rate.
\end{abstract}

Keywords: Economic growth; Thirlwall Law; external constraint.

JEL Classification: F43; O11; C22.

\footnotetext{
* Agradecemos primeiramente à UFSCar, pela oportunidade de realizarmos esse trabalho, o Programa de Pós-Graduação em Economia (PPGEc-UFSCar) e o Departamento de Economia da UFSCar/Sorocaba. Agradecemos também as sugestões de pareceristas e de Geraldo Silva Jr. e Humberto Spolador.

+ Analista de Projetos PL - Departamento de Economia, Competitividade e Tecnologia (DECOMTEC/FIESP). E-mail: erica.mendonca@fiesp.com.br.

‡ Professor Associado III do Departamento de Economia da UFSCar/Sorocaba. Diretor do Centro de Ciências em Gestão e Tecnologia da Universidade Federal de São Carlos, Campus Sorocaba. Email: rvilela@ufscar.br
} 


\section{Introdução}

$\bigcirc$ crescimento econômico é uma temática que tem, ao longo dos anos, impulsionado o debate na área econômica, em especial no que se refere aos seus determinantes e restrições. Constantemente busca-se analisar as razões para as diferenças observadas entre as taxas de crescimento dos países e, mesmo, entre taxas de crescimento do próprio país em diferentes períodos. Nesse sentido, o presente artigo teve como objetivo investigar se a restrição externa foi um fator limitante ao crescimento econômico brasileiro no período entre 1995 e 2010, analisando as diferenças entre os períodos de governo de Fernando Henrique Cardoso (1995-2002) e Luís Inácio da Silva (2003-2010), sob a luz da modelagem de crescimento econômico conhecida como Lei de Thirlwall (LT) e suas posteriores extensões.

Do trabalho seminal desenvolvido por Thirlwall (1979), e no desenvolvimento posterior dessa teoria, com a inclusão de mais variáveis explicativas e aplicações empíricas para diferentes países, desenvolveu-se a interpretação de que, em uma economia aberta, restrições no balanço de pagamentos podem explicar as diferenças nas taxas de crescimento econômico dos países. E, considerando diferentes estudos aplicados para países em desenvolvimento (Thirlwall \& Hussain, 1982; Lopez \& Cruz, 2000; Holland, Vieira \& Canuto, 2004), verificou-se que, em especial, a restrição externa é relevante para explicar trajetória de crescimento desses países.

Para a economia brasileira, que historicamente sofreu com questões relacionadas a desequilíbrios no balanço de pagamentos, como em 1973 e 1979 relacionados ao choques do petróleo e ao aumento dos juros americanos, em 1982 devido à crise da moratória da dívida e em 1999 na crise cambial, entende-se que o arcabouço teórico desenvolvido a partir da LT contribui para interpretar o comportamento do crescimento econômico brasileiro. Por outro lado, mais recentemente, não lidou com impactos tão severos no balanço de pagamentos com a crise internacional de 2008, o que se torna um ponto interessante de análise.

Especificamente para o Brasil, diferentes trabalhos aplicaram a modelagem da LT encontrando evidências de que a restrição externa se impõe como limitante ao crescimento de longo prazo do país. López e Cruz (2000), por exemplo, testaram a validade da LT para quatro países latinos americanos (Argentina, Brasil, Colômbia e México) no período entre 1965 e 1995, com interesse, também, de verificar a importância dos termos de troca na determinação do crescimento dos países, tendo como resultado a validação do modelo para esses países.

Bertola, Higachi e Porcile (2002) estimaram a Lei de Thirlwall original diretamente, incluindo termos de troca, para a economia brasileira no período entre 
1890 e 1973, tendo como resultado a validação da LT para no Brasil no período. Segundo os autores, a escolha deveu-se tanto ao fato de contemplar períodos em que a economia era liderada por exportações (1890-1930), quanto pelo período de substituição de importações (1930-1973), interrompendo a análise em 1973 devido ao fato de o fluxo de capitais ter papel relevante após esse período, o que não é comtemplado pelo modelo utilizado.

Jayme Jr (2003), considerando o período entre 1955 e 1998, testou para a economia brasileira o modelo original de Thirlwall de crescimento econômico com equilíbrio no BP, usando técnica de cointegração e de vetor de correção de erros (VEC), tendo como resultado a validação do modelo. Um ponto interessante sobre esse trabalho deveu-se à estimação da elasticidade renda implícita das importações em períodos diferentes. Por exemplo, a estimação do período 1955-1980 e 1981-1998 demonstra que a elasticidade das importações caiu de 2,58 para 2,50. Agora, comparando o período 1966-1980 com 1981-98, período com maior abertura da economia, a elasticidade aumenta de 2,21 para 2,58, o que sugere que a elasticidade renda das importações pode explicar parte do menor crescimento econômico após 1981.

Essa consideração sobre a diferença da elasticidade no período pré e pós abertura da economia brasileira foi considerado também em Carvalho e Lima (2007). Os autores testaram a validade da LT na economia brasileira para o período entre 1930 e 2004, investigando o papel da estrutura produtiva no crescimento econômico, tendo como resultado que o crescimento no período foi compatível com o equilíbrio no BP, mas que na década de noventa obteve-se uma quebra estrutural da elasticidade renda das importações, muito relacionada às políticas econômicas liberalizantes adotadas nesse período.

Lelis, Silveira e Cunha (2015) e Basso (2014) testaram a validade da LT para período convergente com o presente artigo. Com análise para o período entre os anos 1995 e 2013, Lelis et al. (2015), utilizando o arcabouço teórico da LT original, e através de dois modelos econométricos, sendo eles o vetorial de correção de erros (VAR/VEC), e o modelo estrutural em formato de estado de espaço para o período destacado, verificaram que o balanço de pagamentos foi uma limitação ao crescimento econômico brasileiro. Basso (2014), utilizando dados mensais de 2002 a 2013, verificou a validade da restrição externa ao crescimento econômico para a economia brasileira, concluindo que, ainda que vigente o boom de commodities, o crescimento econômico brasileiro foi restrito pelo balanço de pagamentos. 
Outros avanços da literatura sobre LT deveram-se à aplicação do modelo multissetorial da Lei de Thirlwall, tal como proposto por Araújo e Lima (2007)1. Por exemplo, Soares e Teixeira (2012) testaram a validade da LT multissetorial (LTMS) para o caso brasileiro no período entre 1990 e 2011, a partir de dados trimestrais e anuais, aplicando o instrumental econométrico de séries temporais para a estimação das elasticidades com os dados trimestrais desagregados por categoria de uso e a técnica de estimação em painel para os dados anuais organizados por intensidade tecnológica. Com os resultados obtidos, os autores validaram a LTMS para a economia brasileira no período.

Já abordando o período entre 1962 a 2006, Gouvêa e Lima (2013) testaram também a validade da LTMS para a economia brasileira, porém realizando uma nova classificação setorial para organização dos dados. Assim, com considerações sobre o II PND e utilizando dados anuais, os autores estimaram as elasticidades renda das importações e exportações, agregadas e setoriais, por instrumental econométrico de séries de tempo, tendo como resultado a validação do modelo estatisticamente.

O presente artigo, por sua vez, pretende contribuir com a literatura investigando como a restrição externa impactou de forma distinta a economia brasileira em dois períodos de governo, Fernando Henrique Cardoso (FHC) e Luís Inácio da Silva (Lula), tendo em conta que, apesar de similitudes na condução da política macroeconômica, esses dois governos apresentaram taxas de crescimento econômico diferentes, sendo 2,3\% em média no período 1995-2002 (FHC) e 4,1\% em média no período 2003-2010² (Lula). Dessa forma, pretende-se investigar se também questões relacionadas ao equilíbrio no balanço de pagamentos ajudam a explicar diferenciais de crescimento econômico entre os governos.

E, considerando a relevância dos dois governos no desenvolvimento econômico brasileiro recente, tentou-se abordar como aspectos importantes ocorridos no período, como a estabilização de preços, a mudança de regime cambial em 1999, crises internacionais de confiança, boom de commodities, mudanças nos termos de troca, a ampliação do investimento direto externo, o aumento no nível de reservas e a consequente redução da dívida externa líquida podem estar relacionados a alterações na restrição externa do período.

\footnotetext{
${ }^{1}$ Além da Lei de Thirlwall Multissetorial desenvolvida por Araújo e Lima (2007), podem-se citar outros avanços e discussões na modelagem apresentada, tais como a incorporação da taxa de câmbio real e das elasticidades endógenas, por Ferrari et al. (2013), a incorporação de problemas estruturais como a persistência de assimetrias tecnológicas e heterogeneidade produtiva por Cimoli e Porcile (2014), entre outros.
}

2 IBGE, dados das Contas Nacionais- Ref. 2000. 
Além desta breve introdução, o artigo está organizado em mais cinco seções. A seção subsequente apresenta uma revisão da literatura para o período FHC e Lula. A seção três apresenta a metodologia teórica e empírica adotada, bem como os dados e suas respectivas fontes. A seção quatro apresenta os resultados auferidos e as evidências empíricas encontradas para a restrição externa no governo FHC, no governo Lula e no período completo. Nas considerações finais, apresentam-se as conclusões gerais obtidas pelo presente artigo, bem como sugestão de análises posteriores.

\section{Aspectos macroeconômicos durante os governos FHC e Lula}

Após o período de grande instabilidade política e econômica da década de oitenta, o governo FHC iniciou-se em um contexto favorável devido à desinflação da economia causada pelo sucesso do Plano Real. Porém, como parte do processo realizado com objetivo de controle da inflação, seguiu-se nos primeiros anos da década de noventa uma agenda liberalizante da economia brasileira, com a execução de proposições do que ficou conhecido como Consenso de Washington ${ }^{3}$ (Nakatani \& Oliveira, 2010). Assim, medidas como abertura comercial, redução de tarifas de importação e liberalização da conta capital e financeira que foram adotadas nesse contexto, juntamente com a adoção do Plano Real, tiveram reflexos na condução da política econômica nos períodos seguintes, bem como nos resultados em termos de estrutura produtiva, crescimento econômico, do setor externo e da manutenção de restrições ao crescimento.

Segundo Cunha e Prates (2005), a implementação do Plano Real com utilização do mecanismo de âncora cambial em contexto de elevada liquidez internacional levou a uma sensível apreciação do real. Em conjunto com a redução tarifaria, resultou em déficits comerciais crescentes e, com pouca evolução das exportações, o financiamento externo passou a depender de atração de investimento direto externo, facilitado pelas privatizações, bem como da manutenção de diferenciais de juros internos e externos para atração de investimento de portfólio.

Assim, ao mesmo tempo em que permitiram o sucesso do Plano Real, tais medidas também pioraram as condições de competição dos produtores nacionais de bens tradables em relação aos importados (Tavares, 1997). Essa piora na competição implicou em mudanças na estrutura produtiva da economia brasileira, que como indicado, se refletiram em piora na elasticidade renda das importações. Para Carneiro

\footnotetext{
${ }^{3} \mathrm{O}$ Consenso de Washington foi uma expressão cunhada pelo economista Jonh Williamson após uma conferência patrocinada pelo Banco Mundial em 1989. Ela resume um conjunto de orientações e medidas de política economia que ficaram conhecidas por neoliberalismo e que passou a orientar as recomendações do FMI e do Banco Mundial (Nakatani \& Oliveira, 2010)
} 
(2002), apesar da obtenção da estabilidade de preços, a abertura comercial causou deterioração do saldo comercial, tornando a economia dependente de recursos externos, ponto relevante para modelos com restrição externa como os aplicados no presente artigo.

Em relação aos dados do período, durante o governo FHC se observaram momentos de fuga de capitais e elevação do endividamento, relacionados com a instabilidade financeira gerada pelas crises do leste asiático (1997) e da Rússia (1998), que ampliaram a desconfiança de detentores de ativos de economias emergentes e acarretaram saídas de capitais, o que somado à vulnerabilidade externa da economia brasileira, tornou a política de câmbio sobrevalorizado vigente até então insustentável, culminando na crise cambial brasileira em 1998, seguida da forte desvalorização do real em 1999.

Sob risco de retorno da inflação, realizou-se em 1999 a mudança de regime cambial vigente até o momento, que era o regime de câmbio administrado, para o regime de câmbio flutuante e o estabelecimento do que ficou conhecido como tripé de política econômica: câmbio flutuante, responsabilidade com as contas públicas (geração de superávits primários) e sistema de metas de inflação, sendo essa condução de política macroeconômica mantida posteriormente no governo Lula (Sicsú, 2007).

No final do governo FHC ocorreram ainda outros dois momentos em que se verificou uma instabilidade das contas externas brasileiras. A primeira, em 2001, tendo vários fatores apontados como motivadores, tanto internos à economia brasileira, como o crescimento do passivo externo líquido e a deterioração das contas públicas, quanto fatores externos diretamente relacionados, como a desaceleração dos EUA, principal demandante de produtos brasileiros à época, e o atentado às Torres Gêmeas, que afetou os mercados globais e implicou em saída de capitais (Silva e Lourenço, 2014). A segunda ocorreu em 2002, quando se elevou a instabilidade no mercado em virtude da possibilidade de eleição de Lula, com a suposição que isso poderia acarretar mudanças drásticas na condução macroeconômica, como o calote da dívida. O que também ficou conhecido, na época, como efeito Lula.

Em relação ao governo Lula, este se iniciou em um contexto de crise de confiança externa com sua candidatura, que teve forte impacto no fluxo de capitais de 2002 e na desvalorização cambial, o que se somou à instabilidade ocasionada pela crise Argentina de 2001-2002, e resultou em um novo acordo firmado com o FMI antes de sua posse, com objetivo de evitar nova crise no balanço de pagamentos brasileiro, elevando o endividamento externo (Giambiagi, 2012), mesmo que durante seu governo, uma crise internacional de grande magnitude só ocorreria em 2008. 
E, apesar da dúvida inicial, houve o comprometimento do então candidato à presidência, Lula em honrar compromissos, com a Carta ao Povo Brasileiro, indicando sua nova postura econômica (Giambiagi, 2012). Como já destacado, essa nova postura se refletiu na condução da política econômica semelhante ao governo anterior, com a manutenção do tripé econômico após sua eleição. Mas a despeito dessa similitude na condução macroeconômica, o resultado em termos de balanço de pagamentos divergiu entre os dois governos. Enquanto no governo FHC se observam períodos de resultado negativo no $\mathrm{BP}$, especialmente relacionados às crises citadas, o governo Lula contou com resultados positivos expressivos no $\mathrm{BP}^{4}$

Um aspecto relevante da melhora das contas externas brasileiras relaciona-se ao bom desempenho do balanço comercial no governo Lula, que teve como fator determinante o crescimento econômico mundial significativo que favoreceu a expansão do comercio mundial, bem como a alta nos preços de commodities, resultando em um choque externo benigno para o período (Cunha e Prates, 2005). Destaca-se nesse período o crescimento dos países asiáticos, liderados pela China, que se tornou não apenas um grande produtor de manufaturas industriais, mas também um grande consumidor de manufaturas, alimentos e matérias-primas minerais e energéticas.

Essa maior demanda chinesa beneficiou os exportadores de commodities, entre eles o Brasil, alterando significativamente os termos de troca em favor dos produtos primários principalmente após 2003 (Sarti e Hiratuka, 2011). Dados de comércio exterior mostram que a China figurava como $12^{\circ}$ principal importador de bens e produtos brasileiros. Em 2010 saltou para $1^{a}$ colocação, respondendo por 15,2\% das exportações brasileiras, superando EUA, principal parceiro em 1997.

Outra questão relevante para as contas externas, principalmente no segundo mandato do governo Lula, refere-se ao fluxo de capitais que se manteve significativo, afrouxando a restrição externa sob esse ponto de vista, exceto em 2008, ano da crise econômica mundial. Após 2007 houve crescimento elevado do investimento direto no país e do investimento em carteira, atingindo os respectivos valores de US $\$ 88,5$ bilhões e US\$ 66,9 bilhões em 2010, em comparação aos valores de US $\$ 16,6$ bilhões e US\$ 5,1 bilhões em 2002, último ano do governo FHC. Para Carcanholo (2010), além da melhora nas contas externas, a abundância de liquidez internacional, combinada com a política brasileira de juros altos tornaram o país mais atrativo, o

\footnotetext{
${ }^{4}$ É necessário destacar que o registro das contas do BP sofreu modificações ao longo do tempo, com o objetivo de se alinhar com os registros internacionais. Em 2015 o Brasil passou a adotar a metodologia do Manual de Balanço de Pagamentos (BPM6) do FMI, acarretando algumas diferenças com as estatísticas anteriores de comercio exterior. Em relação ao resultado do BP, este é apontado na linha Ativos de reserva no BPM6.
} 
que permitiu o financiamento da redução do saldo comercial a partir de 2006 e o acúmulo de reservas em larga escala com grande entrada de capitais. Assim, tal comportamento atuou no sentido contrário ao verificado no governo FHC, permitindo o relaxamento da restrição externa do período no governo Lula.

O fato do Brasil ter se tornado credor externo, com a dívida externa líquida em proporção do PIB negativa após 2007, atingindo o percentual de -2,4\% do PIB em 2010, pode ter ajudado, por exemplo, no alívio à restrição ao mercado internacional de financiamento. A melhora nesse indicador, somada ao baixo impacto da crise econômica internacional de 2008 nas contas externas brasileiras resultaram também na obtenção de grau de investimento por agências internacionais de risco em 2008, o que ajuda a explicar esse melhor cenário de acesso ao crédito internacional.

Um ponto a destacar sobre o governo Lula em contraposição ao período anterior refere-se à intenção assumida de redução da vulnerabilidade externa, o que de certo modo se refletiu também no alívio sobre a restrição externa ao crescimento econômico do período. Segundo Giambiagi e Pinheiro (2012), após 2003 houve uma política deliberada das autoridades econômicas destinada a reduzir a vulnerabilidade da economia brasileira a crises externas, política essa associada à redução da dívida interna associada ao dólar, pré-pagamento da dívida com FMI, recompra de Brady Bonds e acumulação de reservas. É possível destacar a ampliação do nível de reservas, que passou de cerca de US\$ 50 bilhões entre 2003 e 2005, para US\$ 289 bilhões em 2010.

Dessa forma, outras questões positivas que não ocorreram no governo FHC se mostraram relevantes no período Lula, como o boom de commodities, a ampliação do investimento direto externo, o aumento no nível de reservas e a consequente redução da dívida externa líquida, sendo estes fatores relevantes do ponto de vista de análise da restrição externa que o artigo se propõe a realizar.

\section{Metodologia}

\subsection{Modelos teóricos: Lei de Thirlwall original e extensões}

Thirlwall (1979) demonstra que a taxa de crescimento de muitos países desenvolvidos se aproximava da taxa de crescimento das exportações dividida pela elasticidade-renda das importações, que, assumindo certas hipóteses, pode ser considerada uma medida de taxa de crescimento com equilíbrio no Balanço de 
Pagamentos (BP). Nessa formulação, que se tornou conhecido na literatura como Lei de Thirwall $(\mathrm{LT})^{5}$, apresenta-se a seguinte relação.

$$
P d_{t} X_{t}=P f_{t} E_{t} M_{t}
$$

Em que $X_{t}$ representa a quantidade de exportações; $P d_{t}$ é o preço das exportações em moeda doméstica; $M_{t}$ se constitui no volume de importações; $P f_{t}$ é o preço das importações, medido em moeda estrangeira; $E_{t}$ representa a taxa de câmbio nominal (preço doméstico da moeda estrangeira); e té o índice de tempo. Destaca-se que apenas o balanço comercial é considerado nessa especificação inicial. Aplicando o logaritmo natural às variáveis em (1) e diferenciando-as em relação ao tempo, obtém-se a condição de equilíbrio em termos de taxas de crescimento de cada variável acima descrita.

$$
p d_{t}+x_{t}=p f_{t}+e_{t}+m_{t}
$$

Assumindo formas multiplicativas tradicionais, com elasticidades constantes, para importações e exportações, tem-se:

$$
\begin{aligned}
& X_{t}=\alpha\left(\frac{P_{d t}}{P_{f} E_{t}}\right)^{\eta} Z_{t}^{\varepsilon} \\
& M_{t}=\beta\left(\frac{P f_{t} E_{t}}{P d_{t}}\right)^{\varphi} Y_{t}^{\pi}
\end{aligned}
$$

Em que $\alpha$ e $\beta$ são constantes positivas; $\eta$ representa a elasticidade-preço da demanda por exportações; $\varphi$ representa a elasticidade-preço da demanda por importações; $Z_{t}$ é a renda mundial; $Y_{t}$ é renda doméstica; $\varepsilon$ constitui-se na elasticidade-renda da demanda por exportações e $\pi$ se constitui na elasticidade-renda da demanda por importações. Expressando as equações (3) e (4) em termos de taxas de crescimento, obtêm-se:

$$
\begin{aligned}
& x_{t}=\eta\left(p d_{t}-e_{t}-p f_{t}\right)+\varepsilon z_{t} \\
& m_{t}=\varphi\left(p f_{t}+e_{t}-p d_{t}\right)+\pi y_{t}
\end{aligned}
$$

\footnotetext{
${ }^{5}$ Como reconhecido por Thirlwall (2011), o desenvolvimento do modelo de crescimento econômico com equilíbrio no BP pode ser relacionado a um conjunto de trabalhos, como a discussão histórica que remonta ao mercantilismo e sua defesa por Keynes, também ao multiplicador de comercio de Harrod, ao modelo centro-periferia de Prebish (2000a,2000b), ao modelo de dois hiatos de Chenery e Bruno (1962) e à crítica sobre como a teoria ortodoxa de comercio e de crescimento negligenciou as consequências do comercio no balanço de pagamentos.
} 
Substituindo as equações (5) e (6) em (2), e isolando y do lado esquerdo da equação, resolve-se para a taxa de crescimento compatível com o equilíbrio no balanço de pagamentos, $y_{b t}$.

$$
y_{b t}=\frac{(1+\eta+\varphi)\left(p d_{t}-e_{t}-p f_{t}\right)+\varepsilon z_{t}}{\pi}
$$

Da equação (6) é possível depreender algumas proposições econômicas

i. A melhoria dos termos de troca, $\left(p d_{t}-e_{t}-p f_{t}\right)>0$, melhora a taxa de crescimento do país de modo compatível com o equilíbrio no BP;

ii. A elevação mais rápida nos preços de um país que dos outros, medida em moeda comum, reduz a taxa de crescimento compatível com equilíbrio no BP desse país, quando a soma das elasticidades preço (negativas) é maior que um, ou seja, $(1+\eta+\varphi)<0$;

iii. A desvalorização da moeda (e>0) eleva a taxa de crescimento compatível com equilíbrio no BP quando a soma das elasticidades preço é maior que um. Mas a depreciação ou desvalorização abrupta da moeda não pode colocar o país em via de crescimento permanentemente maior e compatível com equilíbrio no BP, uma vez que no período seguinte ao da desvalorização ter-se-ia e $=0$, e assim, a taxa de crescimento retornaria ao nível anterior;

iv. A equação indica a interdependência dos países, uma vez que o desempenho de um país em termos de crescimento (y) está ligado ao de todos os outros (z). Contudo, a rapidez com que o país pode crescer em relação aos demais, preservando seu BP, depende crucialmente de $\varepsilon$ (elasticidade renda das exportações).

v. A taxa de crescimento compatível com equilíbrio do BP tem relação inversa com sua demanda por importações, medido por $\pi$.

Adotando-se a hipótese de Paridade do Poder de Compra (PPC), isto é, no longo prazo não há alteração nos termos de troca, de modo que $\left(p d_{t}-e_{t}-p f_{t}\right)=$ 0 , é possível simplificar a equação (7) para.

$$
y_{b t}=\frac{x_{t}}{\pi}
$$

Na qual $x_{t}=\varepsilon z_{t}$. A equação acima, que representa a denominada Lei de Thirlwall, indica que a taxa de crescimento compatível com o equilíbrio no balanço de pagamentos é igual à razão entre o crescimento das exportações e a elasticidade renda das importações 6 .

${ }^{6}$ Ao considerar que $\left(\boldsymbol{p} \boldsymbol{d}_{\boldsymbol{t}}-\boldsymbol{e}_{\boldsymbol{t}}-\boldsymbol{p} \boldsymbol{f}_{\boldsymbol{t}}\right)=\mathbf{0}$, o modelo pressupõe que todo ajuste se dê via renda, descartando ajuste via preços relativos, como realizado pela literatura neoclássica (Carvalho, 2006). 
Thirlwall e Hussain (1982) fizeram a primeira tentativa de incorporar o fluxo de capitais, já que no modelo original o balanço de pagamentos é aproximado apenas pelo balanço comercial. A equação proposta equivale:

$$
P d_{t} X_{t}+F_{t}=P f_{t} M_{t} E_{t}
$$

Em que $F_{t}$ é o valor nominal do fluxo de capital medido em moeda doméstica, sendo $\mathrm{F}>0$ (ou $\mathrm{F}<0$ ) entrada (ou saída) de capitais, e as demais variáveis já definidas anteriormente. Aplicando o logaritmo natural às variáveis da expressão (9), e diferenciando-as em relação ao tempo, obteremos a expressão anterior em termos de taxa de crescimento, como:

$$
\theta\left(p_{d t}+x_{t}\right)+(1-\theta) f_{t}=p_{f t}+e_{t}+m_{t}
$$

Em que $\theta$ e $(1-\theta)$ representam, respectivamente, as parcelas das exportações e dos fluxos de capitais no total das receitas do setor externo. Substituindo as equações (5) e (6) em (10) e isolando y do lado esquerdo da equação, resolve-se para a nova formulação:

$$
y_{b t}=\frac{(\theta \eta+\varphi+1)\left(p_{d t}-p_{f t}-e_{t}\right)+(1-\theta)\left(f-p_{d t}\right)+\theta x_{t}}{\pi}
$$

Em que $y_{b t}$ representa a taxa de crescimento condizente com o equilíbrio externo, incorporando $\mathrm{o}$ influxo de capitais; o termo $\left(f-p_{d t}\right)$ representa $\circ$ crescimento real dos capitais externos (medidos em moeda doméstica); o $\theta$ e o (1- $\theta$ ) são, respectivamente, as parcelas das exportações e dos fluxos de capitais em proporção as receitas externas totais. E, novamente com base na hipótese de que os termos de troca são constantes, ou seja, que $\left(p_{d t}-p_{f t}-e_{t}\right)=0$, a equação (11) pode ser simplificada como segue.

$$
y_{b t}=\frac{(1-\theta)\left(f-p_{d t}\right)+\theta x_{t}}{\pi}
$$

Assim, um aumento na elasticidade-renda das importações pode ser contornado com um maior fluxo de capitais para o país, ou seja, um determinado país poderia incorrer em déficits comerciais na medida em que pudesse financiá-los com capitais externos.

McCombie e Thirlwall (1997) passaram a incorporar na sua análise o endividamento externo, que em Moreno-Brid (1998) teve um desenvolvimento maior, considerando o estoque de endividamento, já que esse estoque corresponderá 
a remessas ao exterior no longo prazo. Nesse mesmo sentido, o modelo desenvolvido por Barbosa-Filho (2001) também destaca a questão da sustentabilidade da dívida, assim como Moreno-Brid (1998).

Moreno-Brid (2003), considerando a crítica sobre a ausência do pagamento de juros no modelo apresentado em Moreno-Brid (1998), passou a incorporar também o serviço de juros da dívida externa. De acordo com esta versão estendida do modelo de Thirlwall e Hussain (1982) realizada por Moreno-Brid (2003), para garantir um equilíbrio de longo prazo consistente com um endividamento sustentável é preciso que a entrada de capitais seja tal que mantenha constante a relação dívida/PIB.

Assim, Moreno-Brid (2003) passou a incorporar também, explicitamente, o pagamento de juros da dívida no equilíbrio externo de longo prazo. Mantendo a condição de endividamento estável, baseada na constância da relação conta corrente/PIB, a modelagem apresentada em 2003 aprimorou o trabalho anterior, uma vez que os resultados encontrados sugerem que a inclusão explícita do serviço da dívida pode, de fato, modificar, expressivamente, o equilíbrio externo de longo prazo.

Considerando as equações (4) e (5), de demanda por importação e exportação, e adaptando a versão apresentada por Thirlwall e Hussain (1982) para incluir de forma explícita o pagamento de juros, o modelo restrito pelo BP derivado por Moreno-Brid (2003) pode ser resumido pelas equações assim especificadas, em termos de taxas de crescimento:

$$
p_{f}+m=\theta_{1}\left(p_{d}+x\right)-\theta_{2}\left(p_{d}+r\right)+\left(1-\theta_{1}+\theta_{2}\right)\left(p_{d}+f\right)^{7}
$$

A equação (13) representa a especificação dinâmica da nova condição de equilíbrio no BP, onde $r$ se constitui no pagamento líquido de juros ao exterior, medido em termos reais; e o $p_{d}+f(=\mathrm{F})$ representa o influxo líquido de capitais externos, medidos em moeda doméstica. A identidade contábil do BP por trás da equação (13) pode ser expressa, em termos nominais, como $M=X-R+F$, onde $M$ representa as importações, $\mathrm{X}$ o total das exportações, $(\mathrm{R}>0)$ o pagamento líquido de juros ao exterior e $\mathrm{F}$ o déficit em conta corrente, que será financiado pela entrada de capital externo (Moreno-Brid, 2003).

\footnotetext{
${ }^{7}$ Em que $\boldsymbol{\theta}_{\mathbf{1}}$ e $\boldsymbol{\theta}_{\mathbf{2}}$ constituem, respectivamente, as seguintes razões, medidas no período inicial: $\boldsymbol{\theta}_{\mathbf{1}}=$ $\left(p_{d} x\right) /\left(p_{f} m\right)$, ou seja, a parcela das despesas com importações garantida pela renda decorrente das exportações $\left(\theta_{-} 1>0\right)$ e $\boldsymbol{\theta}_{\mathbf{2}}=\left(\mathrm{p}_{\mathrm{d}} \mathrm{r}\right) /\left(\mathrm{p}_{\mathrm{f}} \mathrm{m}\right)$, que mostra a proporção do pagamento líquido de juros ao exterior em relação às importações $\left(\boldsymbol{\theta}_{\mathbf{2}}>0\right)$.
} 
Cabe destacar que o fato do $\theta_{2}>0$, ou o sinal negativo do segundo termo do lado direito da equação (14), sugere que o país em questão é um devedor líquido (Moreno-Brid, 2003). E, como $\theta_{1}$ e $\theta_{2}$ são valores positivos, tem-se que o termo $\left(1-\theta_{1}+\theta_{2}\right)$ representa a razão entre o fluxo de capitais externos e as importações.

E para assegurar que a acumulação da dívida externa não seja explosiva, tal como proposto por Moreno-Brid (1998, 2003), é imposta a condição de endividamento sustentável, baseada na manutenção da razão entre o déficit em conta corrente (F) e o PIB (Y):

$$
\mathrm{F} / \mathrm{Y}=\mathrm{k}
$$

em que k é uma constante. Por definição, tem-se que $\mathrm{F}=p_{d}+f$ e $\mathrm{Y}=p_{d}+y$, de modo que, em termos de taxa de variação, a equação (14) pode ser reescrita como

$$
p_{d}+f=p_{d}+y
$$

Substituindo a condição acima na equação (14), resolve-se para a taxa de crescimento condizente com o equilíbrio externo, a qual, além de incorporar o pagamento líquido de juros ao exterior ${ }^{8}$, detém uma trajetória de longo prazo sustentável para a dívida externa acumulada

$$
y *_{b}=\frac{\theta_{1} \varepsilon z-\theta_{2} r+\left(\theta_{1}+\varphi+1\right)\left(p_{d}-e-p_{f}\right)}{\pi-\left(1-\theta_{1}+\theta_{2}\right)}
$$

E, considerando que não há variação dos termos de troca, de modo que, $\left(p_{d}-e-p_{f}=0\right)$ e $(x=\varepsilon z)$, a equação (16) pode ser simplificada para

$$
y *_{b}=\frac{\theta_{1} x-\theta_{2} r}{\pi-\left(1-\theta_{1}+\theta_{2}\right)}
$$

A última formulação destacada refere-se à apresentada por Carvalho e Lima (2007, 2009), a qual destacou, explicitamente, todos os componentes do equilíbrio externo, como a equação 16, porém sem impor estabilização da dívida, de tal forma que corresponderia a seguinte especificação?:

$$
y * *_{b}=\frac{\theta_{1} x+(1+\varphi)\left(p_{d}-e-p_{f}\right)-\theta_{2} r+\left(1-\theta_{1}+\theta_{2}\right) f}{\pi}
$$

em que as letras minúsculas representam as taxas de variação das respectivas variáveis.

\footnotetext{
${ }^{8}$ Segundo Carvalho (2006), ao não separar o pagamento de juros da importação de bens e serviços teria como implicação atribuir ao pagamento de juros o mesmo comportamento da função importação, ou seja, que o pagamento de juros seria crescente na renda e decrescente no câmbio.

9 Em que $\boldsymbol{\theta}_{\mathbf{1}}$ e $\boldsymbol{\theta}_{\mathbf{2}}$ constituem, respectivamente, as seguintes razões, medidas no período inicial: $\boldsymbol{\theta}_{\mathbf{1}}=$ $(\mathrm{Pd} \mathrm{X}) /(\mathrm{Pf} \mathrm{EM})$ e $\boldsymbol{\theta}_{\mathbf{2}}=(\mathrm{Pd} \mathrm{R}) /(\mathrm{PfEM})$.
} 
Analisando os modelos descritos, percebe-se que desde a primeira tentativa feita por Thirlwall e Hussain (1982) de incorporar o fluxo de capitais à LT original, outros autores seguiram apresentando extensões deste modelo, tentando desvendar a trajetória de crescimento das economias em desenvolvimento, incorporando não apenas a conta capital, como também outros componentes do BP, tais como pagamentos dos juros da dívida, dos serviços do capital, além de incluir as condições para o endividamento sustentável (Lezcano, 2012).

\subsection{Dados e fontes}

Os dados referentes ao PIB (Produto Interno Bruto), às importações, às exportações, à conta capital e à taxa de câmbio foram obtidos no site do Banco Central do Brasil (BCB, 2016 a b b c). O índice de preço doméstico medido pelo IPCA, calculado pelo IBGE, disponível no site Ipeadata (2016). Para deflacionar as series em dólar, utilizou-se o IPA americano, disponível no Ipeadata (2016).

Quadro 1. Dados e fontes

\begin{tabular}{|c|c|c|c|c|c|}
\hline Dados & Unidade & Periodicidade & Fonte & & \\
\hline Produto Interno Bruto (PIB) & R\$ bilhões & $\begin{array}{l}\text { Mensal e } \\
\text { anual }\end{array}$ & $\begin{array}{l}\text { Banco } \\
\text { Brasil }\end{array}$ & Central & do \\
\hline Importação (M) & US\$ bilhões & Mensal & $\begin{array}{l}\text { Banco } \\
\text { Brasil }\end{array}$ & Central & do \\
\hline Exportação $(X)$ & US\$ bilhões & Mensal & $\begin{array}{l}\text { Banco } \\
\text { Brasil }\end{array}$ & Central & do \\
\hline Conta Capital (F) & US\$ bilhões & Mensal & $\begin{array}{l}\text { Banco } \\
\text { Brasil }\end{array}$ & Central & do \\
\hline Conta de Serviços (R) & US\$ bilhões & Mensal & $\begin{array}{l}\text { Banco } \\
\text { Brasil }\end{array}$ & Central & do \\
\hline $\begin{array}{l}\text { Índice de Preço Doméstico } \\
\text { (IPCA) }\end{array}$ & Índice & Mensal & Ipeadata & & \\
\hline $\begin{array}{l}\text { Índice de Preço Estrangeiro } \\
\text { (IPA-USA) }\end{array}$ & Índice & Mensal & Ipeadata & & \\
\hline Câmbio nominal (e) & $\mathrm{R} \$ / \mathrm{US} \$$ & Mensal & $\begin{array}{l}\text { Banco } \\
\text { Brasil }\end{array}$ & Central & do \\
\hline Câmbio efetiva real (IPCA) & Índice & Mensal & $\begin{array}{l}\text { Banco } \\
\text { Brasil }\end{array}$ & Central & do \\
\hline
\end{tabular}

Fonte: Elaboração própria com base em dados do BCB (2016, 2016a, 2017) e Ipeadata (2016)

Os dados mensais foram dessazonalizados no Software Eviews, versão 8.0, pelo método Census X-12 $2^{10}$. Para a determinação do componente termos de troca

${ }^{10} \mathrm{O}$ método de ajuste sazonal Census X-12 é um método não paramétrico, recomendado pela ONU e FMI para ajuste de séries econômicas (Zani, 2008). 
utilizou como medida a taxa de câmbio efetiva real (IPCA), disponível no site do Banco Central do Brasil (BCB, 2017).

\subsection{Modelo econométrico}

Um passo importante para a aplicação dos modelos nos períodos considerados no artigo refere-se à estimação da elasticidade renda das importações ${ }^{11}$. Para tal procedimento, utilizou-se o ferramental econométrico referente a séries temporais, uma vez que é imperativo verificar se as variáveis analisadas ao longo do tempo apresentam determinadas características comuns, o que permite estimá-las sem incorrer em regressões espúrias (Enders,2004).

Com os testes de raiz unitária de Dickey-Fuller (DF), Dickey-Fuller Aumentado (ADF), Phillips-Perron (PP) e Kwiatkowski-Phillips-Schmidt-Shin (KPSS), verificou-se a presença de raiz unitária nas séries presentes na função importação (PIB, importação e câmbio efetivo real), tendo como resultado a não estacionariedade das séries envolvidas ${ }^{12}$.

Dado que as séries são não estacionárias, aplicou-se o método de cointegração para identificar se, mesmo na presença de raiz unitária, há uma relação estável (de equilíbrio) de longo prazo entre as variáveis não estacionárias (integradas) que permitisse a estimação da equação pelo Vetor de Correção de Erros (VEC). Utilizando os testes de cointegração de Johansen pelo método do Traço e do Maior Autovalor houve a indicação de presença de cointegração, a 5\% de significância para os três períodos analisados.

Dessa forma, para a equação de importação do período de governo FHC (1995-2002), obteve-se um VAR com 2 defasagens pelo critério SC, lembrando que o VEC possui uma defasagem a menos que o VAR. Para o período Lula (2003-2010), os critérios de informação SC e AIC indicaram um VAR de ordem 1, o que equivale a um VEC de ordem 0. E para o período completo (1995-2010), os critérios de informação LR, FPE e AIC indicaram um VAR de ordem 7, equivalente a um VEC de ordem 6.

Com as estimações das elasticidades-renda e preço, tais valores foram empregados para computar a taxa de crescimento da renda compatível com o equilíbrio no balanço de pagamento, tal como indicado pela LT na sua versão

\footnotetext{
${ }^{11}$ A estimação da função importação foi realizada com base na equação proposta por McCombie (1989), a qual considera as duas variáveis estruturais do modelo, isto é, as elasticidades-renda e preço da demanda por importações (Lezcano,2012). Assim, estimou-se a seguinte função importação, com as variáveis em logaritmo do nível: $\log M_{t}=\pi \log Y_{t}+\psi \log \left(P_{f}+E-P_{d}\right)$.

${ }^{12}$ Uma alternativa seria trabalhar com as séries em primeira diferença e estimá-las com o método de mínimos quadrados ordinários (MOO), porém, como destacado por Jayme Jr (2003), tal método teria como problema não mostrar a relação de longo prazo entre as variáveis.
} 
tradicional, na sua formulação com termos de troca, na versão que inclui influxos de capitais (Thirlwall \& Hussain, 1982), na versão de Moreno-Brid (2003) e, ainda na versão completa do modelo, tal como desenvolvida por Carvalho (2006-2009).

Para a validação dos modelos supracitados, utilizou-se a proposta de Carvalho (2006), a qual sugere a comparação entre as taxas de crescimento previstas pelos modelos teóricos e a taxa de crescimento real da economia ${ }^{13}$. E, para tal comparação, foi aplicado o teste de hipóteses sobre o valor da diferença entre duas médias, utilizando a estatística $t$ de Student (Greene, 2003).

\section{Resultados}

A estimativa de elasticidade renda das importações é o primeiro ponto a ser considerado na análise de restrição externa ao crescimento de longo prazo. Assim, com o método econométrico descrito na seção anterior, obtiveram-se os resultados para as elasticidades dos períodos, sendo os parâmetros significativos, conforma demonstrado na Tabela 1.

Tabela 1. Equações de Longo prazo (VEC) para as Importações - Período FHC, Lula e 1995 a 2010

\begin{tabular}{|c|c|c|c|c|}
\hline Período & Variável & $\beta$ & Erro padrão () & t-statistics [ ] \\
\hline \multirow{7}{*}{$\begin{array}{l}\text { Período } \\
\text { FHC (1995 } \\
\text { a 2002) }\end{array}$} & PIB & $-2,579$ & $(0.37168)$ & {$[-6.94016]^{* *}$} \\
\hline & Câmbio_real & 0,775192 & (0.11434) & {$[6.77955]^{* *}$} \\
\hline & Constante & 20,18215 & & \\
\hline & Correção de erros: & D(imp) & $\mathrm{D}($ pib) & D(cambio_real) \\
\hline & CointEq1 & -0.248455 & 0.078494 & -0.052239 \\
\hline & & $(0.09210)$ & (0.02835) & (0.04598) \\
\hline & & {$[-2.69762]$} & {$[2.76901]$} & {$[-1.13625]$} \\
\hline
\end{tabular}

${ }^{13} \mathrm{O}$ teste de validação da LT adotado teve sua inspiração em McCombie (1989), que propôs como o teste de validade da Lei de Thirlwall a comparação da elasticidade-renda hipotética (elasticidade que iguala a taxa de crescimento observada com a teórica) e a elasticidade-renda estimada a partir da função de importação, de forma que a igualdade entre as taxas validaria a LT. 
Tabela 1. Equações de Longo prazo (VEC) para as Importações - Período FHC, Lula e 1995 a 2010 (Continuação)

\begin{tabular}{|c|c|c|c|c|}
\hline \multirow{7}{*}{$\begin{array}{l}\text { Período Lula } \\
\qquad(2003 \text { a } \\
2010)\end{array}$} & PIB & $-1,648$ & $(0.36170)$ & {$[-4.55741]^{* *}$} \\
\hline & Câmbio_real & 0,967436 & $(0.26124)$ & {$[3.70327]^{* *}$} \\
\hline & Constante & 7,442209 & & \\
\hline & Correção de erros: & $\mathrm{D}(\mathrm{imp})$ & $\mathrm{D}($ pib) & D(cambio_real) \\
\hline & CointEq1 & $-0,351508$ & -0.044174 & 0.036326 \\
\hline & & $(0.07441)$ & $(0.01686)$ & $(0.03200)$ \\
\hline & & {$[-4.72364]$} & {$[-2.61953]$} & [1.13509] \\
\hline \multirow{7}{*}{$\begin{array}{l}\text { Período } \\
\text { completo } \\
(1995 \text { a } \\
2010)\end{array}$} & PIB & $-2,519$ & $(0.25690)$ & {$[-9.80532]^{* *}$} \\
\hline & Câmbio_real & 0,811835 & $(0.20435)$ & {$[3.97278]^{* *}$} \\
\hline & Constante & 19,01201 & -323318 & {$[5.88028]^{* *}$} \\
\hline & Correção de erros: & $\mathrm{D}(\mathrm{imp})$ & $\mathrm{D}($ pib) & D(cambio_real) \\
\hline & CointEq1 & -0.047095 & -0.028474 & -0.005761 \\
\hline & & $(0.02405)$ & $(0.00574)$ & $(0.01190)$ \\
\hline & & {$[-1.95851]$} & [-4.95996] & {$[-0.48406]$} \\
\hline
\end{tabular}

Fonte: Elaboração própria com dados do Software Eviews. Nota: $\beta$ se refere ao parâmetro estimado. ** significativo a $5 \%$.

Os resultados da tabela acima podem ser resumidos nas seguintes equações de demanda das importações

$$
\begin{aligned}
& \text { 1995-2002: } \log M_{t}=2,58 \log Y_{t}-0,77 \log \left(P_{f}+E-P_{d}\right) \\
& \text { 2003- 2010: } \log M_{t}=1,65 \log Y_{t}-0,96 \log \left(P_{f}+E-P_{d}\right) \\
& \text { 1995-2010: } \log M_{t}=2,51 \log Y_{t}-0,81 \log \left(P_{f}+E-P_{d}\right)
\end{aligned}
$$

Nesse sentido, um ponto a destacar sobre a elasticidade-renda das importações de 2,58, estimada para o período FHC (1995 a 2002), refere-se a sua proximidade com a elasticidade calculada por Jayme Jr (2003), de 2,50 entre 1981 e 1998. Comparando-se com a elasticidade de 1,60, calculada por Lopez e Cruz (2000) e a de 1,22, calculada por Carvalho e Lima (2009), para períodos anteriores às políticas adotadas no início da década de noventa, o resultado encontrado pelo presente trabalho também sugere uma piora na elasticidade renda das importações no período pós abertura da economia.

A elasticidade renda das importações de 1,65, estimada para o período Lula (2003 a 2010), ficou em um patamar intermediário entre as estimações de 1,27 de 
Basso (2014) para o período entre 2002 e 2013, a qual utilizou metodologia de estimação semelhante à aplicada no artigo, e a estimada em 3,31 por Nassif et al. (2015) para o período entre 1999 e 2010.

Destaca-se a redução da elasticidade renda das importações no período Lula em comparação ao período FHC. Quanto menor a elasticidade renda das importações, menor é seu impacto na redução do crescimento pelos modelos a la Thirlwall. Enquanto para o período FHC estimou-se uma elasticidade renda das importações de 2,58, para o período Lula obteve-se uma elasticidade renda das importações de 1,65, indicando uma melhora nesse componente do modelo, o que representa uma menor restrição externa ao crescimento no período Lula.

Um debate que pode surgir desse resultado diz respeito a alguma mudança na estrutura produtiva que justifique tal modificação na elasticidade. Autores como Nassif et al. (2015), Carvalho e Carvalho (2011), Bresser e Marconi (2009) e Milani (2011) apontam que havia indícios de que a economia brasileira caminhava para um processo de especialização regressiva nos anos 2000, com redução da participação dos setores manufaturados e ampliação da participação na economia de setores intensivos em recursos naturais ou setores com menor valor agregado, o que contrariaria o resultado de menor elasticidade renda das importações no governo Lula. Mas tal conclusão é contestada por Urraca-Ruiz, Brito e Souza (2013) que, avaliando a estrutura industrial brasileira entre 1996 e 2011, alegam não haver evidências para afirmar que a economia tenha alterado significativamente sua estrutura produtiva nesse período.

Quando se observa a produção industrial, com objetivo de entender a reação do setor produtivo nos diferentes períodos, verifica-se que a indústria de transformação obteve melhor desempenho no governo Lula. Enquanto a taxa de crescimento média da produção da indústria de transformação no período FHC foi de 1,3\%, no período Lula passou para 3,2\%, com destaque para o crescimento elevado na produção de bens de capital em quase todos os anos do período, com exceção de 2009, ano seguinte à crise econômica mundial. Tal resultado positivo do setor industrial pode ser relacionado tanto à desvalorização cambial ocorrida em 1999, quanto ao crescimento da demanda doméstica, pelo consumo e investimento, o que beneficiou a expansão de um conjunto mais amplo de setores industriais, sobretudo os setores de bens salários e de bens de capital (Sarti e Hiratuka, 2011). Ou seja, a indústria obteve bom desempenho durante o período, o que talvez tenha influenciado conjunturalmente o resultado da elasticidade renda das importações.

E com as estimativas de elasticidades renda e preço das importações obtidas, calcularam-se as taxas de crescimento teóricas dos modelos da LT, para os três 
períodos analisados, em seis versões dos modelos da LT: o modelo 1 refere-se à versão original; o modelo 2 é a versão original considerando os termos de troca; o modelo 3 refere-se à LT com fluxo de capitais; o modelo 4 é a versão completa do modelo com todas variáveis explicitamente; o modelo 5 refere-se à versão completa excluindo os termos de troca e, por fim, o modelo 6 refere-se à versão Moreno-Brid (2003), que inclui o pagamento de serviços de capitais e limite ao endividamento. Obtiveram-se, assim, os seguintes resultados.

Tabela 2. Resultados dos modelos LT para período FHC, Lula e período completo

\begin{tabular}{c|c|c|c|c|c|c|c}
\hline & $\begin{array}{c}\text { Média } \\
\text { cresc. } \\
\text { PIB }\end{array}$ & $\begin{array}{c}\text { Modelo 1 } \\
\text { LT } \\
\text { original }\end{array}$ & $\begin{array}{c}\text { Modelo 2 } \\
\text { LT original } \\
\text { com termos } \\
\text { de troca }\end{array}$ & $\begin{array}{c}\text { Modelo 3 } \\
\text { LT com } \\
\text { fluxo de } \\
\text { capitais }\end{array}$ & $\begin{array}{c}\text { Modelo 4 } \\
\text { Versão } \\
\text { Carvalho- } \\
\text { Lima }\end{array}$ & $\begin{array}{c}\text { Modelo 5 } \\
\text { Modelo 4 } \\
\text { s/ termos } \\
\text { troca }\end{array}$ & $\begin{array}{c}\text { Modelo 6 } \\
\text { Versão } \\
\text { Moreno- } \\
\text { Brid } \\
(2003)\end{array}$ \\
\hline $\begin{array}{c}1995 \text { a 2002 } \\
\text { (FHC) }\end{array}$ & 2,30 & $1.97^{* *}$ & $2,79^{* *}$ & 0,27 & 0.19 & -0.63 & $1.52^{* *}$ \\
$\begin{array}{c}2003 \text { a 2010 } \\
\text { (Lula) }\end{array}$ & 4,06 & 7,54 & 7,33 & 9,80 & 10,74 & 10,95 & $5,87^{* *}$ \\
\begin{tabular}{c}
1995 a 2010 \\
\hline
\end{tabular} & 3.10 & $3.46^{* *}$ & $3.44^{* *}$ & $3,15^{* *}$ & $2,94^{* *}$ & $2,97^{* *}$ & $2.52^{* *}$ \\
\hline
\end{tabular}

Fonte: Elaboração própria Nota: ${ }^{*}$ Significativo a $5 \%$ com base na estatística $t$-Student

Para o período FHC foram validados os modelos que consideram apenas o lado comercial do BP (modelos 1 e 2), e o modelo que inclui pagamento de serviços do capital e impõe limite ao endividamento (modelo 6). Destaca-se que foram obtidas as maiores taxas de crescimento teóricas justamente nos dois primeiros modelos, possivelmente por desconsiderarem outros componentes do BP que se mostraram relevantes no período, como fluxos de capital e serviços do capital. Já o modelo 6 incorreu em uma taxa de crescimento de 1,52\%, menor que a efetiva e àquelas calculadas nos modelos anteriores, indicando que o pagamento dos serviços da dívida e o limite ao endividamento ampliaram a restrição ao crescimento econômico no período.

Realmente houve ampliação do pagamento do serviço do capital entre o início e fim do governo FHC, passando de US\$10,7 bilhões em 1995 para US \$ 17,7 bilhões em $2002^{14}$. Além disso, como observado no gráfico 1, ampliou-se também a relação dívida líquida/PIB até 2002, o que explicaria a maior restrição ao crescimento considerando esses componentes. Porém, o erro de previsão do modelo em relação aos dados observados pode sugerir que tais restrições não se concretizaram, apesar de relevantes para o período. Possivelmente, a obtenção de empréstimos com o FMI,

${ }^{14}$ BCB (2016a). 
com consequente elevação do endividamento, como apontado por Giambiagi e Pinheiro (2012), foi um fator relevante para afrouxar a restrição externa imposta pelo endividamento.

Gráfico 1. Dívida externa líquida/PIB (\%) - 1995 a 2010

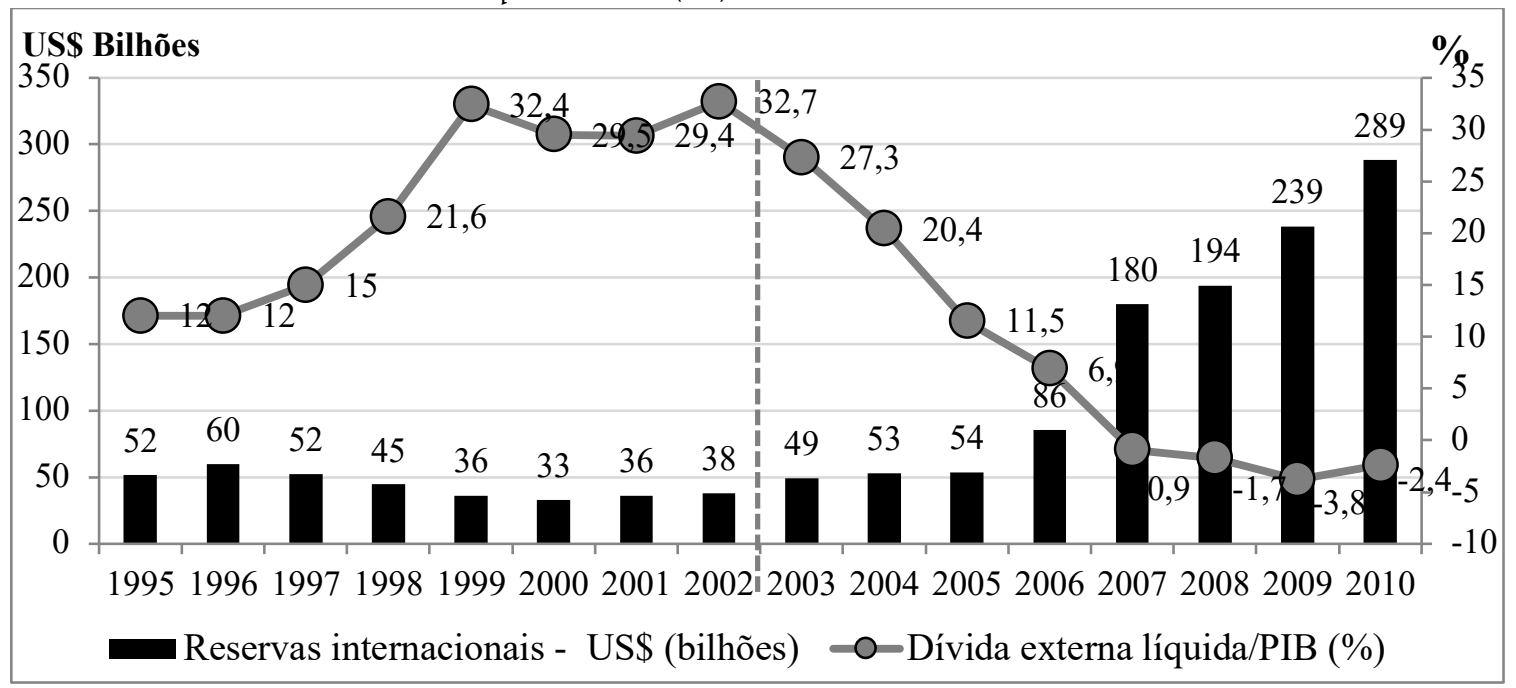

Fonte: Elaboração própria com base em dados do BCB (2017).

Para o período Lula foi validado o modelo que considera o pagamento dos serviços do capital e impõe limite ao endividamento (modelo 6). Destaca-se, porém, a maior taxa teórica obtida pelo modelo, de 5,87\% em comparação à taxa real observada e em relação ao período FHC. Ou seja, comparando os dois períodos observa-se que o endividamento apresentou efeito inverso em relação à restrição externa do período, sendo esta efetivamente menor no período Lula.

Finalmente, observando o período completo, de 1995 a 2010, foram validados todos os modelos testados, a 5\% de significância. Indicando que o equilíbrio no balanço de pagamentos manteve-se como uma restrição ao crescimento econômico brasileiro de longo prazo. Assim como no período FHC, no período completo os modelos que consideram apenas o lado comercial do BP (modelos 1 e 2) apresentaram as maiores taxas teóricas, possivelmente por não tratarem de outros componentes que interferem na restrição externa e que tiveram grande relevância no período, como o fluxo de capitais, o pagamento de serviços do capital e o endividamento.

Para o período completo é importante observar que mesmo os modelos que nos períodos Lula e FHC, separadamente, não se mostraram válidos, ao avaliar o período mais longo essas diferenças são dissipadas, indicando que a restrição externa está estruturalmente presente na economia brasileira. Ou seja, ainda que no período Lula a restrição externa tenha sido relaxada em comparação ao período FHC, ao apresentar taxas de crescimento teóricas superiores, há evidências de que 
continuaram desempenhando um papel relevante na taxa de crescimento de longo prazo do Brasil.

Por fim, considerando o modelo que apresenta explicitamente todos os componentes do BP (modelo 4), foi possível utilizá-lo para decompor ${ }^{15}$ as variáveis do modelo, tendo como objetivo verificar sua participação no resultado estimado, como verificado na tabela 3.

Tabela 3. Decomposição do modelo (4) de crescimento com equilíbrio no BP

\begin{tabular}{c|c|c|c|c|c}
\hline & Mod. 4 & Exportações & Termos troca & Serviços Dívida & Capitais \\
\hline $\begin{array}{c}\text { Cresc. médio } \\
\text { (\%) } 1995-2010\end{array}$ & $2,94 \%$ & 2,62 & $-0,02$ & $-0,49$ & 0,83 \\
\hline
\end{tabular}

Fonte: Elaboração própria com base no resultado do modelo 3.

Dessa forma, analisando os componentes do modelo individualmente, temse que as exportações tiveram a maior contribuição para o crescimento obtido pelo modelo teórico, de 2,62 p.p. Tal resultado reflete o que se verificou na economia brasileira no decorrer do período, com salto das exportações de US $\$ 46,4$ bilhões em 1995 para US $\$ 201,3$ bilhões em 2010, relacionado principalmente ao crescimento das exportações de commodities, bem como pela valorização nos preços desses bens em decorrência da forte demanda mundial.

Os fluxos de capitais também resultaram em uma contribuição positiva no crescimento do período completo, de 0,83 p.p., indicando que a entrada de capitais ao longo do período permitiu que tal componente relaxasse a restrição externa ao crescimento econômico de longo prazo brasileiro. Ainda que o período entre 1995 e 2010 tenha sido marcado por crises que acarretaram em saída de capitais e elevação do endividamento, em especial no governo FHC, após 2007 houve um crescimento acentuado de fluxos de capitais para o Brasil, tanto em carteira quanto de investimento direto estrangeiro, atingindo os respectivos valores de US $\$ 88,5$ bilhões e US $\$ 66,9$ bilhões em 2010, em comparação aos valores de US $\$ 16,6$ bilhões e US\$ 5,1 bilhões em 2002, último ano de governo FHC, o que explicaria o resultado positivo para esse componente do modelo.

O componente termos de troca, por sua vez, que é representado pela taxa de câmbio efetiva real, forneceu uma contribuição negativa de $-0,02$ p.p. para o crescimento segundo o modelo. Esse resultado negativo pode ser entendido pela tendência de apreciação cambial no período completo. Como observado no gráfico

\footnotetext{
${ }^{15}$ Foi realizada a decomposição do modelo sem considerar o peso de cada variável no PIB, ou seja, não está se medindo a contribuição de cada variável no crescimento do período, mas sim em que medida cada termo se refletiu no modelo, considerando sua taxa de crescimento em relação à elasticidade renda das importações.
} 
2, no período entre 1995 e 2010, o câmbio manteve-se apreciado até 1998, devido ao mecanismo de âncora cambial, mas mesmo com a desvalorização de 1999, posteriormente o câmbio voltou a se apreciar e impactar o resultado comercial negativamente.

Gráfico 2. Evolução do índice da taxa de câmbio efetiva e do índice de câmbio real (R\$/US\$)

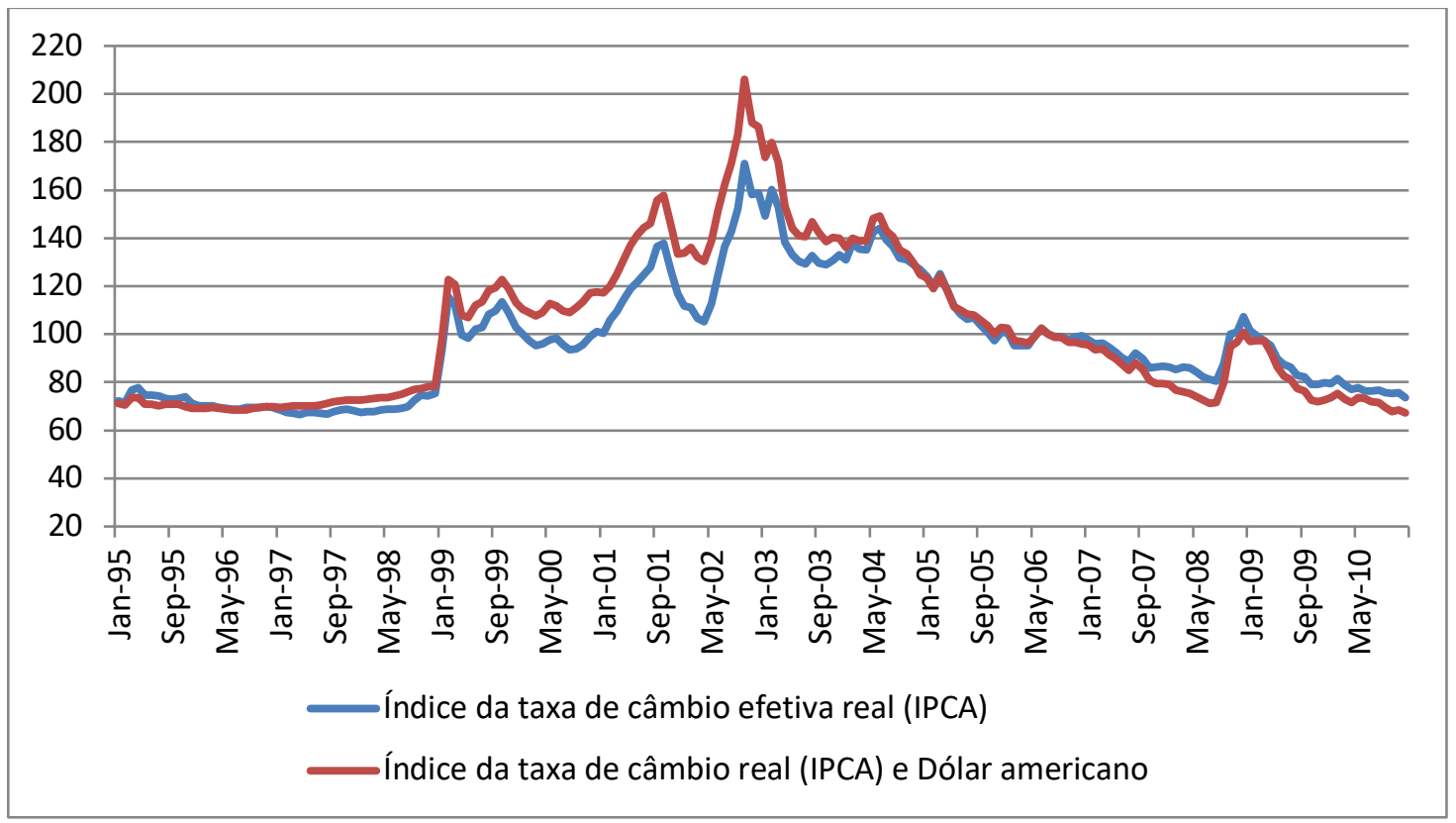

Fonte: Elaboração própria com base em dados do BCB (2016a).

Já os pagamentos de serviços da dívida reduziram em 0,49 p.p. o crescimento obtido pelo modelo teórico. Nesse aspecto, o crescimento do pagamento de lucros e dividendos no governo Lula contribui para esse resultado, uma vez que essa conta passou de US\$2,9 bilhões em 1995 para US \$ 55,5 bilhões em 2010. Já o pagamento de juros ficou na média entre US $\$ 10$ e US\$ 11 bilhões nos dois períodos de governo, indicando que se sustentou como uma restrição relevante do ponto de vista de necessidade de divisas, porém sem grandes oscilações.

Historicamente, o déficit na conta primária relaciona-se com o modelo de desenvolvimento adotado no país, fundamentado em financiamento externo e em empresas multinacionais. Assim, como resultado dessa própria presença de empresas multinacionais na economia brasileira em oposição à baixa internacionalização das nossas empresas, o item Lucros e dividendos já era deficitário no período anterior a análise do artigo. Esse item, apesar de deficitário, não apresentou grandes variações no governo FHC. Já no governo Lula, como indicado na tabela 4, a conta renda primária passou a apresentar déficits ainda maiores, principalmente a partir de 2005, em função também do crescimento no pagamento de lucros e dividendos. 
Tabela 4. Evolução conta Renda Primária brasileira- 1995-2010 (US\$ milhões correntes)

\begin{tabular}{l|r|r|r|r|r|r|r|r|}
\hline & \multicolumn{1}{|c|}{$\mathbf{1 9 9 5}$} & \multicolumn{1}{|c|}{$\mathbf{1 9 9 6}$} & \multicolumn{1}{|c|}{$\mathbf{1 9 9 7}$} & $\mathbf{1 9 9 8}$ & \multicolumn{1}{|c|}{$\mathbf{1 9 9 9}$} & $\mathbf{2 0 0 0}$ & \multicolumn{1}{c|}{$\mathbf{2 0 0 1}$} & \multicolumn{1}{c|}{$\mathbf{2 0 0 2}$} \\
\hline Renda primária & $\mathbf{- 1 0 . 7 4 7}$ & $\mathbf{- 1 1 . 3 7 4}$ & $\mathbf{- 1 4 . 5 7 6}$ & $\mathbf{- 1 7 . 8 4 0}$ & $\mathbf{- 1 8 . 4 8 1}$ & $\mathbf{- 1 7 . 4 8 1}$ & $\mathbf{- 1 9 . 3 0 7}$ & $\mathbf{- 1 7 . 7 1 8}$ \\
Rem. de empregados & -160 & -60 & 50 & 103 & 142 & 79 & 95 & 102 \\
Juros & -7.636 & -8.484 & -9.182 & -11.088 & -14.509 & -14.244 & -14.441 & -12.658 \\
Lucros e dividendos & -2.951 & -2.830 & -5.443 & -6.855 & -4.115 & -3.316 & -4.961 & -5.162 \\
\hline & $\mathbf{2 0 0 3}$ & $\mathbf{2 0 0 4}$ & $\mathbf{2 0 0 5}$ & $\mathbf{2 0 0 6}$ & $\mathbf{2 0 0 7}$ & $\mathbf{2 0 0 8}$ & $\mathbf{2 0 0 9}$ & $\mathbf{2 0 1 0}$ \\
\hline Renda primária & $\mathbf{- 1 8 . 1 3 5}$ & $\mathbf{- 2 0 . 1 0 7}$ & $\mathbf{- 2 5 . 5 5 3}$ & $\mathbf{- 2 6 . 9 8 5}$ & $\mathbf{- 2 9 . 0 0 2}$ & $\mathbf{- 4 1 . 8 0 6}$ & $\mathbf{- 3 4 . 9 8 3}$ & $\mathbf{- 6 7 . 0 5 5}$ \\
Rem. de empregados & 109 & 181 & 214 & 177 & 448 & 545 & 603 & 498 \\
Juros & -12.603 & -12.950 & -13.081 & -10.794 & -7.015 & -8.476 & -10.368 & -11.993 \\
Lucros e dividendos & -5.640 & -7.338 & -12.686 & -16.369 & -22.435 & -33.875 & -25.218 & -55.560 \\
\hline
\end{tabular}

Fonte: Elaboração própria com base em dados do BCB (2016).

Esse resultado na conta Lucros e dividendos é relacionado ao próprio crescimento do fluxo de investimento direto no país que voltou a ocorrer após 2005 e atingiu seu ápice em 2010. Ou seja, com o crescimento do investimento direto no país houve a contrapartida de retorno desses investimentos em forma de lucros e dividendos. Assim, nota-se que a restrição imposta pelos serviços do capital foi significativamente superior no governo Lula em relação ao governo FHC, muito mais em razão dos pagamentos com Lucros e dividendos do que em relação ao pagamento de juros.

Em resumo, mesmo que a elevação do nível de reservas e a redução significativa do indicador dívida externa líquida/PIB após 2007 tenham melhorado a resposta da economia brasileira a crises e a flutuações externas, a restrição externa ao crescimento econômico manteve-se como uma questão estrutural da economia brasileira, ainda dependente de entrada de fluxos externos para equilibrar déficits em transações correntes e os pagamentos de serviços do capital. Sendo tal análise coerente com a validação de todos os modelos que testaram a LT para o período completo.

\section{Conclusões}

Os resultados encontrados sugerem que a restrição externa se manteve como um limitante do crescimento econômico de longo prazo no Brasil no período entre 1995 e 2010. Porém, avaliando separadamente os governos FHC e Lula, verifica-se um relaxamento da restrição externa neste último.

Concentrando a análise dos resultados no comportamento da elasticidade renda das importações, importante componente da LT, houve uma redução da elasticidade renda das importações no governo Lula, estimada em 1,65, em relação à elasticidade de 2,58 estimada para o governo de FHC. Tal resultado permite inferir que houve uma redução da restrição externa sob esse ponto de vista no período Lula. 
Tendo em conta o debate existente sobre mudança na estrutura produtiva brasileira, uma investigação futura sobre a elasticidade renda das importações setoriais pode contribuir para entender o ocorrido no período. Porém, considerando a redução da participação da indústria na economia ocorrida até o presente, sem contrapartida de aumento em serviços de alta tecnologia, é possível avaliar que a mudança na elasticidade renda das importações tenha sido um fato conjuntural do período Lula, convergente com o bom desempenho da economia mundial nesse período.

Em relação à aplicação dos modelos, obteve-se como resultado que, tanto para o governo FHC quanto para o governo Lula manteve-se válida a hipótese de restrição externa considerando que houve a validação de pelo menos um modelo. Para o período completo, por sua vez, houve a validação de todos os modelos, indicando que diferenças entre os períodos foram dissipadas quando consideradas dentro de um prazo maior.

Um ponto a destacar, avaliando todos os resultados obtidos para os modelos testados nos períodos FHC e Lula, é que a inclusão do componente fluxo de capitais, explicitamente, apresentou resultados opostos entre os dois governos. Enquanto no governo FHC a inclusão do fluxo de capitais no modelo original tornou o resultado teórico inferior ao obtido com os dados observados e com o modelo original, no governo Lula apresentou-se uma taxa teórica superior à verificada com dados reais. Mas considerando o período completo o modelo de Thirlwall e Hussain (1982) mostrou-se válido, indicando que tais divergências entre os períodos podem ter sido diluídas no tempo, e que o fluxo de capitais afrouxou a restrição externa no período.

Em síntese, analisando empiricamente a economia brasileira para os dois períodos de governo, houve indícios de que a restrição externa da economia brasileira se deslocou favoravelmente de um período de graves crises externas, como no governo FHC, para um período com melhores condições externas, marcado pelo boom de commodities, como o governo Lula, em que a grave crise internacional de 2008 teve um impacto menor na restrição externa ao crescimento do que as crises internacionais anteriores.

Porém, a validade de ao menos um modelo nesses dois períodos, separadamente, confirma a hipótese de restrição externa ao crescimento da economia brasileira nesses períodos. E, considerando o período completo, mesmo com a melhora dos indicadores de vulnerabilidade externa da economia brasileira, explicitados principalmente na redução da dívida externa líquida, verificou-se a manutenção da restrição externa como uma condição estrutural da economia brasileira, sendo, portanto, um fator ainda não completamente superado. 


\section{Referências}

Araujo, R. A., \& Lima, G. T. (2007). A structural economic dynamics approach to balance-of-payments-constrained growth. Cambridge Journal of Economics, 31(5), 755-774. https://doi.org/10.1093/cje/bem006

Barbosa-Filho, N. (2001). The balance of payments constraint: from balanced trade to sustainable debt. BNL Quarterly Review, 54(219), 381-400. Disponível em

https://ojs.uniroma1.it/index.php/PSLQuarterlyReview/article/view/9952/9 833

Basso, M. C. (2014). A Economia Brasileira sob Restrição do Balanço de Pagamentos: Uma Análise Empírica da Lei de Thirlwall no Boom das Commodities. In Anais do XIII Encontro Nacional de Economia (p. 21). Natal: ANPEC Associação Nacional dos Centros de Pós-graduação em Economia. Disponível em https:/www.anpec.org.br/encontro/2014/submissao/files_I/i614a6d1c176 165032efe027070e360813.pdf

BCB - Banco Central do Brasil. (2016). Séries Históricas do Balanço de Pagamentos. Brasilia: Banco Central do Brasil. Disponível em http://www.bcb.gov.br/htms/infecon/Seriehist_bpm6.asp\%3E

BCB - Banco Central do Brasil. (2016a). Sistema gerenciador de séries temporais. Brasilia: Banco Central do Brasil. Disponível em https://www3.bcb.gov.br/sgspub/localizarseries/localizarSeries.do?method =prepararTelaLocalizarSeries \%3E

BCB - Banco Central do Brasil. (2017). Sistema gerenciador de séries temporais. Brasilia: Banco Central do Brasil. Disponível em https://www3.bcb.gov.br/sgspub/localizarseries/localizarSeries.do?method =prepararTelaLocalizarSeries \%3E

Bértola, L., Higachi, H., \& Porcile, G. (2002). Balance-of-payments-constrained growth in Brazil: A test of Thirlwall's Law, 1890-1973. Journal of Post Keynesian Economics, 25(1), 123-140. https://doi.org/10.1080/01603477.2002.11051348

Bresser-Pereira, L. C., \& Marconi, N. (2009). Doença Holandesa e Desindustrialização. Valor Econômico, p. 4. Disponível em 
http://www.bresserpereira.org.br/Articles/2009/09.11.25.Doenca_holandes a_e_desindustrializacao.pdf

Carcanholo, M. D. (2010). Inserção externa e vulnerabilidade da economia brasileira no governo Lula. In Os anos Lula: contribuiçôes para um balanço crítico 2003-2010 (pp. 109-131). Rio de Janeiro: Garamond.

Carneiro, R. (2002). Desenvolvimento em crise: a economia brasileira no último quarto do século XX (1a ed.). São Paulo: Editora Unesp/IE Unicamp.

Carvalho, D. F., \& Carvalho, A. C. (2011). Desindustrialização e reprimarização da economia brasileira contemporânea num contexto de crise financeira global: conceitos e evidências. Revista Economia Ensaios, 201), 35-64. Disponível em http://www.seer.ufu.br/index.php/revistaeconomiaensaios/article/ viewFile/17548/12179

Carvalho, V. R. da S. (2006). A restrição externa e a perda de dinamismo da economia brasileira: investigando as relações entre estrutura produtiva e crescimento econômico. Dissertação (Mestrado em Economia), Universidade de São Paulo, São Paulo. https://doi.org/10.11606/D.12.2006.tde-05102006104604

Carvalho, V. R. da S., \& Lima, G. T. (2007). A restrição externa e a perda de dinamismo da economia brasileira: investigando relações entre estrutura produtiva e crescimento econômico. In Anais do XXXV Encontro Nacional de Economia da ANPEC (p. 20). Recife, PE: ANPEC - Associação Nacional dos Centros de Pós-graduação em Economia. Disponível em http://www.anpec.org.br/encontro2007/artigos/A07A013.pdf

Carvalho, V. R. da S., \& Lima, G. T. (2009). Estrutura produtiva, restrição externa e crescimento econômico: a experiência brasileira. Economia e Sociedade, 18(1), 31-60. https://doi.org/10.1590/s0104-06182009000100002

Chenery, H. B., \& Bruno, M. (1962). Development Alternatives in an Open Economy: The Case of Israel. The Economic Journal, 72(285), 79. https://doi.org/10.2307/2228618

Cimoli, M., \& Porcile, G. (2014). Technology, structural change and BOPconstrained growth: A structuralist toolbox. Cambridge Journal of Economics, 38(1), 215-237. https://doi.org/10.1093/cje/bet020

Cunha, A. M., \& Prates, D. M. (2005). A política econômica do Governo Lula e o ajuste nas contas externas. Indicadores Econômicos FEE, 33(1), 5-40. 
Disponível em https://revistas.fee.tche.br/index.php/indicadores/article/ view/1076/1405

Enders, W. (2004). Applied econometric Time Series (2a ed.). Hoboken, NJ: John Wiley.

Ferrari, M. A. R., Freitas, F. N. P., \& Filho, N. B. (2013). A taxa de câmbio real e a restrição externa: Uma proposta de releitura com elasticidades endógenas. Revista de Economia Politica, 33(1), 60-81. https://doi.org/10.1590/S010131572013000100004

FUNCEXDATA (2017). Estatísticas de Comércio Exterior. Rio de Janeiro: Fundação Centro de Estudos de Comércio Exterior. Disponível em http://www.funcexdata.com.br

Giambiagi, F., \& Pinheiro, A. C. (2012). Além da euforia: riscos e lacunas do modelo brasileiro de desenvolvimento (1a ed.). Rio de Janeiro: GEN LTC.

Gouvêa, R. R., \& Lima, G. T. (2013). Mudança estrutural e crescimento sob restrição externa na economia brasileira: uma análise empírica do período 1962-2006 com considerações sobre o II PND. Economia e Sociedade, 22(1), 107-139. https://doi.org/10.1590/s0104-06182013000100004

Greene, W. H. (2003). Econometric Analysis (5a ed.). New Jersey: Prentice-Hall.

Holland, M., Vilela Vieira, F., \& Canuto, O. (2004). Economic Growth and the Balance-of-Payments Constraint in Latin America. Investigación Económica, 63(247), 45-74.

IPEADATA. (2016). Série de Dados Macroeconômicos. Rio de Janeiro: IPEA. Disponível em http://ipeadata.gov.br/

Jayme Jr., F. G. (2003). Balance-of-Payments-Constrained Economic Growth in Brazil. Revista de Economia Política, 23(189), 62-84. Disponível em http://www.rep.org.br/pdf/89-4.pdf\%3Forigin\%3Dpublication_detail

Lelis, M. T. C., Silveira, E. M. C., \& Cunha, A. M. (2015). Crescimento e Restrição Externa em Tempos de Especialização Regressiva: uma análise para o Brasil no período 1995-2013. In Anais do XLIII Encontro Nacional de Economia ANPEC (p. 20). Florianópolis, SC: ANPEC - Associação Nacional dos Centros de Pós-graduação em Economia. Disponível em http://www.anpec.org.br/encontro/2015/submissao/files_I/i610b2577ffb70 be8a48ecc963e4ffc5a5.docx 
Lezcano, J. M. (2012). Modelos de crescimento sob restrições externas: uma abordagem à la Thirlwall para o Mercosul. UFSCAR - Campus de Sorocaba. Disponivel em https://repositorio.ufscar.br/handle/ufscar/2146

López G., J., \& Cruz B., A. (2000). "Thirlwall's Law” and Beyond: The Latin American Experience. Journal of Post Keynesian Economics, 22(3), 477-495. https://doi.org/10.1080/01603477.2000.11490253

Mccombie, J. S. L. (1989). 'Thirlwall's Law' and balance of payments constrained growth - a comment on the debate.' Applied Economics, 21(5), 611-629. https://doi.org/10.1080/758524894

Mccombie, J. S. L., \& Thirlwall, A. P. (1997). Economic growth and the balance of payments constraint revisited. In P. Arestis, G. Palma, \& M. Sawyer (Eds.), Markets, unemployment and economic policy: essays in honour of $G$. Harcourt, v.2 (1st ed., pp. 498-512). Abingdon, Oxon: Routledge. https://doi.org/10.4324/9780203982518

Milani, A. (2011). Questões para se pensar o desenvolvimento no Brasil: especialização regressiva e pauta exportadora no período de 2003-2010. In Anais do I Circuito de Debates acadêmicos Ipea e Associações de Pósgraduação em Ciências Humanas (p. 19). Brasília: IPEA. Disponível em http://www.ipea.gov.br/code2011/chamada2011/pdf/area4/area4artigo6.pdf

Moreno-Brid, J. C. (1998). On capital flows and the balance-of-paymentsconstrained growth model. Journal of Post Keynesian Economics, 21(2), 283-298. https://doi.org/10.1080/01603477.1998.11490194

Moreno-Brid, J. C. (2003). Capital Flows, Interest Payments and the Balance-ofPayments Constrained Growth Model: A Theoretical and Empirical Analysis. Metroeconomica, 54(2-3), 346-365. https://doi.org/10.1111/1467-999X.00170

Nakatani, P., \& Oliveira, F. A. (2010). Política econômica brasileira de Collor a Lula: 1990-2007. In M. Ferreira \& R. Marques (Eds.), O Brasil sob uma nova ordem: a economia brasileira contemporânea: uma análise dos governos Collor a Lula (1a ed., pp. 21-50). São Paulo: Saraiva.

Nassif, A., Feijó, C., \& Araújo, E. (2015). Structural change and economic development: Is Brazil catching up or falling behind? Cambridge Journal of Economics, 395), 1307-1332. https://doi.org/10.1093/cje/beu052 
Prebisch, R. (2000a). O desenvolvimento da economia da América Latina e alguns de seus problemas principais. In R. Bielschowsky (Org.), Cinqüenta anos de pensamento na Cepal (1a ed., pp. 69-136). Rio de Janeiro: Record. Disponivel em https://repositorio.cepal.org/bitstream/handle/11362/1607/ S33098N962Av2_pt.pdf? sequence $=2$ \&isAllowed $=y$

Prebisch, R. (2000b). Problemas teóricos e práticos do crescimento econômico. In R. Bielschowsky (Org.), Cinqüenta anos de pensamento na Cepal, v.1 (1a ed., pp. 179-215). Rio de Janeiro: Record. Disponível em https://repositorio.cepal.org/bitstream/handle/11362/1607/S33098N962Av 2_pt.pdf? sequence $=2$ \&is Allowed $=y$

Ruiz, A. U., Britto, J. N. de P., \& Souza, K. S. G. de. (2013). Qualificando o caráter 'regressivo' da especialização industrial do Brasil. Revista Econômica, 15(1), 115-139. https://doi.org/10.22409/economica.15i1.p60

Sarti, F., \& Hiratuka, C. (2011). Desenvolvimento industrial no Brasil oportunidades e desafios futuros (No. 187). Texto para discussão IE/UNICAMP. Campinas, SP. Disponível em https://tinyurl.com/vu9f6gj

Sicsú, J. (2007). Rumos e definições da política econômica brasileira: do plano A de FHC para o plano A+ de Lula. In J. Sicsú, Emprego, juros e câmbio - Finanças globais e desemprego (p. 376). Rio de Janeiro: Campus.

Silva, J. A. da, \& Lourenço, A. L. C. de. (2014). Restrição Externa: A Economia Brasileira na Década Recente e o Modelo de Thirlwall. Revista Economia \& Tecnologia, 1044), 9-35. https://doi.org/10.5380/ret.v10i4.38160

Soares, C., \& Teixeira, J. R. (2012). A Lei de Thirlwall Multissetorial: novas evidências para o caso brasileiro. In Anais do XL Encontro Nacional de Economia ANPEC (p. 20). Porto de Galinhas, PE: ANPEC - Associação Nacional dos Centros de Pós-graduação em Economia. Disponível em http://www.anpec.org.br/encontro/2012/inscricao/files_I/i50b65cbe90575a 664c7fad6367e00372e.pdf

Tavares, M. C. (1997). A economia política do Real. In A. Netto \& A. Mercadante (Eds.), O Brasil pós-Real: a política econômica em debate (pp. 101-129). Campinas, SP: Instituto de Economia da Universidade Estadual de Campinas.

Thirlwall, A. P. (1979). The balance of payments constraint as an explanation of international growth rates differences. Banca Nazionale Del Lavoro 
Quarterly Review, 32(128), 45-53. Disponível em https://ojs.uniroma1.it/ index.php/PSLQuarterlyReview/article/view/12804/12609

Thirlwall, A. P. (2011). Balance of payments constrained growth models: history and overview. PSL Quartely Review, 64(259), 307-351. Disponível em https://ojs.uniroma1.it/index.php/PSLQuarterlyReview/article/view/9404/9 299

Thirlwall, A. P., \& Hussain, M. N. (1982). The balance of payments constraint, capital flows and growth rate differences between developing countries. Oxford Economic Papers, 34(3), 498-510. https://doi.org/10.1093/oxfordjournals.oep.a041565

Zani, S. C. (2008). Filtros ótimos que conservam qualquer ordem de tendência. Pontifícia Universidade Católica do Rio de Janeiro. https://doi.org/10.17771/PUCRio.acad.12167 